\title{
Designing Hybrid Intelligence Based Recommendation Algorithms: An Experience Through Machine Learning Metaphor
}

\author{
Arup Roy \\ Birla Institute of Technology, Mesra, India \\ E-mail: aruproy.cse@gmail.com
}

Thesis summary

Keywords: recommendation system, hybrid intelligent system, optimization, machine learning

Received: August 12, 2019

\begin{abstract}
This article presents a summarization of the doctoral thesis, which proposes efficient hybrid intelligent algorithms in recommendation systems. The development of effective recommendation algorithms for ensuring quality recommendation in a timely manner is a tricky task. Moreover, the traditional recommendation system is inadequate to cope up with the new technological trends. To overcome these issues, a batch of sophisticated recommendation systems has been discovered e.g. contextual recommendation, group recommendation, and social recommendation. The research work investigates and analyzes new genres of recommenders using nature-inspired algorithms, evolutionary algorithms, swarm intelligence algorithms, and machine learning techniques. The algorithms resolve some crucial problems of these recommenders. As a result, the more personalized recommendation is ensured.

Povzetek: Povzetek doktorske disertacije, ki predlaga učinkovite hibridne inteligentne algoritme $v$ priporočenih sistemih, raziskuje in analizira nove zvrsti priporočil z uporabo algoritmov po naravnih vzorih, evolucijskih algoritmov, algoritmov z roji in tehnik strojnega učenja.
\end{abstract}

\section{Introduction}

Recommendation from known sources assist to achieve unknown tasks, e.g. purchasing of products, making plans for vacation, etc. However, verbal assurance often lacks real-time information and consequences contradicting opinions. Consequently, users are overwhelmed by the voluminous information, and the possibility of opting wrong products could increase. Recommendation System (RS) becomes functional in such situations, e.g. movie recommendation of movielens.org, music recommendation of last.fm, product recommendation of amazon.com [1][2]. An RS lessens, the "information overload" problem as well as provide quick personalized recommendations [3]. Technically, the recommendation process consists of collecting user preferences, tracking the relevant data, and executing the recommendation algorithms [4].

The thesis presents intelligent recommendation models considering real-life applications viz., movies, ecommerce, restaurants, hotels, and matrimonial sites using learning algorithms, nature-inspired algorithms and meta-heuristics optimizations. The initial chapters of the thesis propose a new group and contextual recommendation algorithms. The final few chapters depict performance optimization algorithms.

\section{Methodology}

The thesis deals with designing hybrid intelligent algorithms using soft computing techniques, bio-inspired algorithms, and probabilistic models. Specifically, the research introduces (a) Crowd-Sourcing based Group Recommendation Framework: a modified termite colony based hybrid movie recommendation framework is introduced to minimize the scalability problem, recommendation of high quality products, and minimization of the recommendation time[5] (b) Trusted Contextual Recommendation Framework: a fish school search algorithm based model is proposed to ensure the recommendation from reputed users, and a reduction of the recommendation hazards using artificial bee colony based simulated annealing algorithm[6] (c) Functional Retail Recommendation Framework: a termite colony based optimized model is introduced for product recommendation, predicted of stocks based on product consumption pattern, and prediction to increase the overall selling[7] (d) New Collaborative Filtering Framework: a rough-dragonfly hybrid is proposed to find the optimal neighbors of the active user, accurate rating prediction, and removal of data sparsity issue[8] (e) New Vista in Demographic Filtering Framework: a $\mathrm{K}$-means-ant colony hybrid is introduced to recommend the best partners in matrimonial sites, intelligent noisy data removal mechanism prior to recommendation, and intelligent classification of the significant attributes[9].

\section{Results}

In (a) Crowd-Sourcing based Group Recommendation Framework: The well-known Movie-Lens dataset is used in the experimentation purpose. The metrics such as Mean Absolute Error and Root Mean Squared Error have been used to test the error in the predicted rating. 
Moreover, the proposed content based filtering has been compared with the Jaccard, Tanimoto, and Binary Cosine techniques. The experimental results show promising results compared to these techniques. In (b) Trusted Contextual Recommendation Framework: The Irish Trip-Advisor dataset is used in the experimentation. Moreover, the AOL data set is used for the verification of proper access operations. Particularly, location and time are considered as contextual features. The parameters reputation of a user, recommendations to a user, degree of impact, and fitness are considered to demonstrate the effectiveness of the proposed algorithm. In (c) Functional Retail Recommendation Framework: The transactional dataset (13 distinct values) from a UKbased online retail store is used in experimentation purpose. The parameters frequency of selling, repeat purchase, number of purchases, and total selling frequency assisting to predict the pattern of the stock in the near future. In (d) New Collaborative Filtering Framework: The model is trained using Restaurant and Consumer data of the Recommender Systems Domain. Subsequently, metrics such as Coverage, Root Mean Squared Error, Precision, F-Measure, and Reliability demonstrates the effectiveness of the proposed model. In (e) New Vista in Demographic Filtering Framework: The first 100 demographic profiles of the prospective brides and grooms from the popular Indian matchmaking website SimplyMarry.com is considered for the validation purpose. The metrics such as Success Rate and Recall depicts the efficiency of the proposed algorithm.

\section{Conclusion and Future Work}

The thesis proposes some novel ideas and implementations to envisage recommendations. To achieve this, the research exhibit intelligent recommendations through learning. It successfully gets rid of some inherent limitations such as detection of intruders, recommendation generation, rating prediction, neighbor selection, and matching of the user profiles. The frameworks have been proposed in view of some real-life applications such as movies, e-commerce, restaurants, hotels, and matrimonial sites. As a result, researches become more vibrant and exciting. Moreover, the models could be easily plugged into commercial recommenders. Although, the researches show promising results, some improvements need to be taken care of such as utility-based recommendations, good consensus functions for group recommenders, management of big data, robust algorithms to efficiently deal with the fuzzy, ambiguous, and non-deterministic information.

\section{References}

[1] Will Hill, Larry Stead, Mark Rosenstein, and George Furnas, Recommending and evaluating choices in a virtual community of use, in: Proceedings of the
SIGCHI Conference on Human Factors in Computing Systems, 194-201, 1995.

https://doi.org/10.1145/223904.223929

[2] Paul Resnick, Neophytos Iacovou, Mitesh Suchak, Peter Bergstrom, and John Riedl, GroupLens: An open architecture for collaborative filtering of netnews, in: Proceedings of the ACM Conference on Computer Supported Cooperative Work, 175-186, 1994.

https://doi.org/10.1145/192844.192905

[3] David Goldberg, David Nichols, Brian M. Oki, and Douglas Terry, Using collaborative filtering to weave an information, Communications of the ACM, 35(12): 61-70, 1992.

https://dl.acm.org/doi/10.1145/138859.138867

[4] Keunho Choi, Donghee Yoo, Gunwoo Kim, and Yongmoo Suh, A hybrid online-product recommendation system: Combining implicit ratingbased collaborative filtering and sequential pattern analysis, Electronic Commerce Research and Applications, 11(4): 309-317, 2012. https://doi.org/10.1016/j.elerap.2012.02.004

[5] Arup Roy, Soumya Banerjee, Chintan Bhatt, Youakim Badr, Sourav Mallik, Hybrid group recommendation using modified termite colony algorithm: A context towards big data, Journal of Information and Knowledge Management, 17(2), 2018. https://doi.org/10.1142/S0219649218500193

[6] Arup Roy, Madjid Tavana, Soumya Banerjee, Debora Di Caprio, A secured context aware tourism recommender system using artificial bee colony and simulated annealing, International Journal of Applied Management Science, 8(2): 93-113, 2016. https://dx.doi.org/10.1504/IJAMS.2016.077014

[7] Soumya Banerjee, Neveen I. Ghali, Arup Roy, Aboul Ella Hassanein, A bio-inspired perspective towards retail recommender system: Investigating optimization in retail inventory, in: Proceedings of the IEEE International Conference on Intelligent Systems Design and Applications, 161-165, 2012. https://doi.org/10.1109/ISDA.2012.6416530

[8] Arup Roy, Soumya Banerjee, Manash Sarkar, Ashraf Darwish, Mohamed Elhoseny, Aboul Ella Hassanein, Exploring new vista of intelligent collaborative filtering: A restaurant recommendation paradigm, Journal of Computational Science, 27(1); 168-182, 2018. https://doi.org/10.1016/j.jocs.2018.05.012

[9] Arup Roy, Soumya Banerjee, Who will be my dearest one? An expert decision, International Journal of Advanced Intelligence Paradigm (In Press). 